\title{
Guidelines for Management of Analgesics after Caesarean Section: Cognitive Survey

\author{
Eleonora Storti ${ }^{1 *}$, Silvia Vaccari ${ }^{2}$, Raffaele Bruno ${ }^{3}$, Alba Ricchi ${ }^{4}$, Jessica Buffagni ${ }^{5}$ and \\ Isabella Neri
}

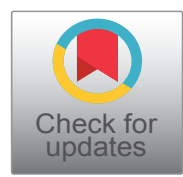

${ }^{1}$ School Student of the Midwifery Department of Medical and Surgical Sciences, University of Modena and Reggio Emilia, Italy ${ }^{2}$ Deputy President of National Federation of the Professional Associations of Midwifery, Italy

${ }^{3}$ Gynecologist of Mother-Infant Department, Hospital of Sassuolo, Italy

${ }^{4}$ Coordinator of the Midwifery Department of Medical and Surgical Sciences, University of Modena and Reggio Emilia, Italy ${ }^{5}$ Midwife of Mother-Infant Department, Hospital of Sassuolo, Italy

${ }^{6}$ Gynecologist of Mother-Infant Department, Azienda Ospedaliero-Universitaria Policlinico di Modena, Italy

*Corresponding author: Eleonora Storti, School Student of the Midwifery Department of Medical and Surgical Sciences, University of Modena and Reggio Emilia, Italy

\begin{abstract}
Objective: To identify the most effective analgesic plan to minimise the perception of pain of the woman subjected to caesarean section.

Material and methods: Experimental Case-control study. The 76 women of the "case" received timed multimodal therapy. In addition, the same sample received a satisfaction questionnaire with items concerning the psycho-physical wellbeing of women in relation to the treatment plan being used. The "control" group, also made up of 76 women who had recently given birth, was subjected to the unimodal analgesic plan as required. Mothers' pain of both groups was registered every day of hospitalisation by the same parameter: "VAS".

Results: The $p$-value is not statistically significant on day 0 , on day 2 and on day 3 . This means that the two analgesic treatments can be overlapped in order to obtain the pre-established outcome. However, the only statistically significant datum is the VAS measured on day I. Therefore, a timed therapeutic approach was found to be more effective in the management of post-operative pain on day 1 as regards the need for analgesic.

Conclusions: From what emerged from the study, adequate pain control is needed mostly in the 24 hours following the operation: in this phase, the woman who has just delivered a child reports a higher level of pain, presumably due to increased mobilisation and partial recovery of the physiological functions.
\end{abstract}

\begin{abstract}
However, the two treatment models are effective in the reduction of post-operative pain, although both treatments do not seem to be sufficient to achieve the prefixed outcome in the first day of hospitalisation.

Summary: Good pain control in women after childbirth improves the psycho-physical wellbeing of the mother-child dyad and reduces the possibility of chronic pain and post-partum depression.
\end{abstract}

\section{Keywords \\ Postpartum, Caesarean section, Pain, Analgesia, VAS}

\section{Introduction}

The term puerperium is used to indicate a time span that varies from six to eight weeks after childbirth, necessary for the woman's body to return to the conditions it was in before the pregnancy. Independently of its actual duration, the puerperium is a very delicate phase of the woman's life, with possible physical and psychological implications. What characterises this period is also the experience of pain. It is therefore important that all health workers who follow the woman at this particular moment of her life make sure to protect her well-being and promote the family's emotional bond.

In this regard, the components of pain after a cae-

Citation: Storti E, Vaccari S, Bruno R, Ricchi A, Buffagni J, et al. (2018) Guidelines for Management of Analgesics after Caesarean Section: Cognitive Survey. Int J Womens Health Wellness 4:075. doi. org/10.23937/2474-1353/1510075

Accepted: August 16, 2018: Published: August 18, 2018

Copyright: (C) 2018 Storti E, et al. This is an open-access article distributed under the terms of the Creative Commons Attribution License, which permits unrestricted use, distribution, and reproduction in any medium, provided the original author and source are credited. 
sarean section were analysed: Somatic and visceral. Somatic pain results from direct trauma of tissues due to surgical incision, while visceral pain is caused by inflammation [1]. A lot of studies have been conducted in favour of the use of several types of drugs in the treatment of pain following childbirth, sometimes associated with the administration of opioids like morphine. The purpose of this analgesia is to minimise the woman's perception of pain, to improve her well-being, encourage breastfeeding and to make the hospital stay as pleasant as possible, minimising the onset of post-partum depression [1].

After delivery, women may experience different types of pain and discomfort such as intermittent uterine cramp pain, pain at the incision site after a caesarean section, perineal pain following trauma, breast-feeding nipple pain, mastitis, headache or lower back pain [2].

Adequate post-operative pain control reduces the patient's average hospital morbidity, mortality and hospitalisation time by implementing the outcome. Frequent measurement of pain is necessary in order to evaluate the efficacy of the treatment administered.

Caesarean delivery is correlated to acute post-operative pain and evidence shows an association with the development of chronic pain, increased use of opioids, delayed recovery of the functions and increased post-partum depression [3]. The use of multimodal analgesia, which uses a combination of different drugs with a different mechanism of action, is aimed at achieving better pain relief and minimising its side effects [4]. Numerous studies of the post-caesarean period have shown the supremacy of multimodal analgesia over the treatment with a single drug.

This is the reason that let us hypothesize that maybe a multimodal therapy could be more effective after C-section than unimodal plan to minimize the pain during the first days of postpartum. We used VAS parameter to evaluate the pain level of women after Caesarean Section.

\section{Materials and Methods}

The study is based on data collected from 12/11/2016 to $01 / 09 / 2017$. It falls within the type of "RCT case-control" trials: The first sample consists of the population of the experimental arm, which is administered timed multimodal analgesic therapy (Table 1 and Table 2) (FANS associated with the use of morphine), adopted by the hospital from March 2017. The data were compared with those related to the second category, subjected to the

Table 1: Multimodal plan spinal anaesthesia.

\begin{tabular}{|c|c|c|}
\hline \multirow{3}{*}{ Day 0} & Acetaminophen $1 \mathrm{gr}$ IV & 3 times a day \\
\hline & Ranitidine $50 \mathrm{mg}+$ Ondansetron $4 \mathrm{mg}+0.9 \% \mathrm{NaCl} 100 \mathrm{ml}$ & 2 times a day \\
\hline & Ketorolac $15 \mathrm{mg} \mathrm{IV}+0.9 \% \mathrm{NaCl} 100 \mathrm{ml}$ & $2 / 3$ times a day only if VAS $\geq 4$ \\
\hline \multirow{4}{*}{ Day 1} & Ibuprofen 600 mg per OS & 2 times a day \\
\hline & Ranitidine $150 \mathrm{mg}$ per OS + Metoclopramide $10 \mathrm{mg}$ per OS & $1 \mathrm{~h}$ before breakfast, lunch and dinner \\
\hline & $\begin{array}{l}\text { Morphine s.c. } \\
-3 \mathrm{mg}<90 \mathrm{~kg} \\
-5 \mathrm{mg}>90 \mathrm{~kg}\end{array}$ & 3 times a day only if VAS $\geq 4$ \\
\hline & Acetaminophen $1 \mathrm{gr}$ per OS & 3 times a day only if VAS $\geq 4$ \\
\hline \multirow{3}{*}{ Day 2} & Ibuprofen 600 mg per OS & 2 times a day \\
\hline & Ranitidine $150 \mathrm{mg}$ per OS + Metoclopramide $10 \mathrm{mg}$ per OS & $1 \mathrm{~h}$ before breakfast, lunch and dinner only if needed \\
\hline & Acetaminophen $1 \mathrm{gr}$ per OS & 3 times a day only if VAS $\geq 4$ \\
\hline Day 3 & Ibuprofen 600 mg per OS & 2 times a day only if VAS $\geq 4$ \\
\hline
\end{tabular}

Table 2: Multimodal plan general anaesthesia.

\begin{tabular}{|c|c|c|}
\hline \multirow{6}{*}{ Day 0} & Acetaminophen $1 \mathrm{gr}$ IV & 3 times a day \\
\hline & Elastomeric pumps with: & \\
\hline & -Ketorolac & During DAY 0 and DAY 1 \\
\hline & -Morphin & \\
\hline & $-0.9 \% \mathrm{NaCl}$ & \\
\hline & Ketorolac $15 \mathrm{mg} \mathrm{IV}+0.9 \% \mathrm{NaCl} 100 \mathrm{ml}$ & $2 / 3$ times a day only if $V A S \geq 4$ \\
\hline \multirow{6}{*}{ Day 1} & Ibuprofen 600 mg per OS & 2 times a day \\
\hline & Ranitidine $150 \mathrm{mg}$ per OS + Metoclopramide $10 \mathrm{mg}$ per OS & $1 \mathrm{~h}$ before breakfast, lunch and dinner \\
\hline & Morphine s.c. & \\
\hline & $-3 \mathrm{mg}<90 \mathrm{~kg}$ & 3 times a day only if VAS $\geq 4$ \\
\hline & $-5 \mathrm{mg}>90 \mathrm{~kg}$ & \\
\hline & Acetaminophen $1 \mathrm{gr}$ per OS & 3 times a day only if VAS $\geq 4$ \\
\hline \multirow{3}{*}{ Day 2} & Ibuprofen 600 mg per OS & 2 times a day \\
\hline & Ranitidine $150 \mathrm{mg}$ per OS + Metoclopramide $10 \mathrm{mg}$ per OS & $1 \mathrm{~h}$ before breakfast, lunch and dinner only if needed \\
\hline & Acetaminophen $1 \mathrm{gr}$ per OS & 3 times a day only if VAS $\geq 4$ \\
\hline Day 3 & Ibuprofen 600 mg per OS & 2 times a day only if VAS $\geq 4$ \\
\hline
\end{tabular}


Table 3: Unimodal plan.

\begin{tabular}{|l|l|l|}
\hline Day 0 & Acetaminophen $1 \mathrm{gr} \mathrm{IV}$ & Maximum 3 times a day only if VAS $\geq 4$ \\
\hline Day 1 & $\begin{array}{l}\text { Acetaminophen } 1 \mathrm{gr} \text { per OS } \\
\text { or } \\
\text { Ketoprofene } 50 / 100 \mathrm{mg} \text { per OS }\end{array}$ & Maximum 3 times a day only if VAS $\geq 4$ \\
\hline Day 2 & $\begin{array}{l}\text { Acetaminophen } 1 \mathrm{gr} \text { per OS } \\
\text { or } \\
\text { Ketoprofene } 50 / 100 \mathrm{mg} \text { per OS }\end{array}$ & Maximum 3 times a day only if VAS $\geq 4$ \\
\hline Day 3 & $\begin{array}{l}\text { Acetaminophen } 1 \mathrm{gr} \text { per OS } \\
\text { or } \\
\text { Ketoprofene } 50 / 100 \mathrm{mg} \text { per OS }\end{array}$ & Maximum 3 times a day only if VAS $\geq 4$ \\
\hline
\end{tabular}

Patient Name: Date:

\section{Visual Analog Scale (VAS)*}

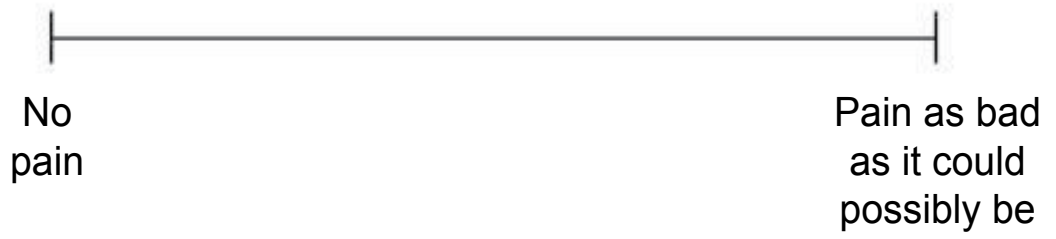

${ }^{*} \mathrm{~A} 10 \mathrm{~cm}$ baseline is recommended for VAS scales.

From: Acute Pain Management: Operative or Medical Procedures and Trauma, Clinical Practice Guideline No. 1.

AHCPR Publication No. 92-0032; February 1992. Agency for Healthcare Research \& Quality, Rockville, MD; pages 116-117.

Figure 1: Visual Analog Scale (VAS)*.

unimodal treatment plan as needed (Table 3) (administration of a single type of NSAID, protocol in force at the hospital until February 2017). The type of sampling used in the study on analgesic treatment after a caesarean section is simple, i.e. it may include all the units of the population (patients undergoing caesarean section). The outcome to be analysed is therefore the effectiveness of one therapy rather than the other in the management of post-operative pain.

In order to achieve the object of the study, the VAS (Visual Analog Scale) was analysed in the various days of hospitalisation, dividing it between the two samples. The VAS consists of a line, the extremes of which represent the concepts of "no pain" and "worst possible pain" or "severe/very severe pain". The woman is asked to indicate the level of her pain on the line within the two limits. The distance between the "no pain" and the level indicated by the patient defines the level of subjective pain. This tool was used for the first time in psychology by Freud in 1923 (Figure 1).

This parameter was measured by consulting the medical records of the mothers who had undergone a caesarean section. The variable was then divided into two categories $(<4, \geq 4)$, the second of which involves the administration of analgesic therapy (control group) or the rescue drug (case group).

The data obtained from the evaluation of pain intensity were integrated with other characteristics contained in the woman's medical record, such as age, level of education, ethnicity, type of anaesthesia and caesarean section, parity, labour and/or use of oxytocin and breast-feeding.

A questionnaire with relative informed consent was used to identify the degree of satisfaction of the women after childbirth as regards the new analgesic protocol, which consists in a review of the Brief Pain Inventory [5]: This tool quantifies the intensity of pain as well as the disability it causes the patient. It consists of a series of questions concerning the intensity and the consequent functional limitation. The questionnaire contains items such as pain relief, autonomous management of the new-born, interference of the obstetrician in the family relationship and the achievement of psycho-physical well-being. The compilation was done by the women who had just given birth included in the experimental arm, who received the new analgesic scheme adopted by the clinic.

\section{Description of the samples}

The two groups, case and control, consisting of the 


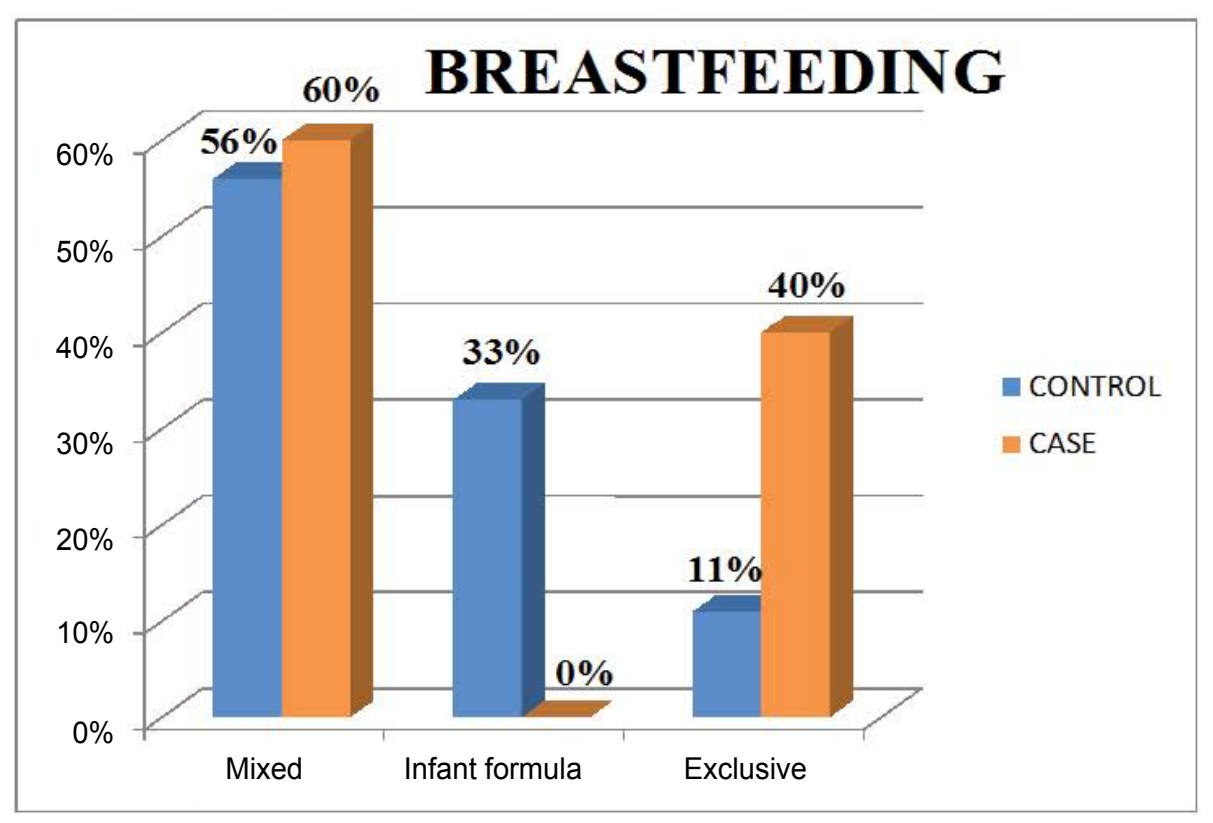

Figure 2: Breastfeeding.

Table 4: Description of the samples.

\begin{tabular}{|c|c|c|c|}
\hline Categories & Cases (76) & Controls (76) & P-Value \\
\hline -Age $\geq 35$ years & $38(50 \%)$ & $32(42.1 \%)$ & \multirow[t]{2}{*}{0.329 (NS) } \\
\hline -Age $<35$ years & $38(50 \%)$ & $44(57.9 \%)$ & \\
\hline -Nulliparous & $33(43.4 \%)$ & $29(38.2 \%)$ & \multirow{3}{*}{0.738 (NS) } \\
\hline -Primiparous & $31(40.8 \%)$ & $32(42.1 \%)$ & \\
\hline -Multiparous & $12(15.8 \%)$ & $15(19.7 \%)$ & \\
\hline -Middle school & $19(25 \%)$ & $17(22.4 \%)$ & \multirow{4}{*}{0.312 (NS) } \\
\hline -High school & $39(51.3 \%)$ & $31(40.8 \%)$ & \\
\hline -Graduated & $16(21.1 \%)$ & $23(31.3 \%)$ & \\
\hline -Elementary school & $2(2.6 \%)$ & $5(6.6 \%)$ & \\
\hline -Elective C-section & $39(51.3 \%)$ & $29(38.2 \%)$ & \multirow{3}{*}{0.257 (NS) } \\
\hline -Urgent C-section & $35(46.1 \%)$ & $45(59.2 \%)$ & \\
\hline $\begin{array}{l}\text {-Emergency } \\
\text { C-section }\end{array}$ & $2(2.6 \%)$ & $2(2.6 \%)$ & \\
\hline $\begin{array}{l}\text {-C-section without } \\
\text { labour }\end{array}$ & $68(89.5 \%)$ & $64(84.2 \%)$ & \multirow[t]{2}{*}{0.337 (NS) } \\
\hline -C-section in labour & $8(10.5 \%)$ & $12(15.8 \%)$ & \\
\hline $\begin{array}{l}\text {-Use of oxytocin in } \\
\text { labour/early signs }\end{array}$ & $5(6.6 \%)$ & $4(5.3 \%)$ & 0.731 (NS) \\
\hline -LR anaesthesia & $70(92.1 \%)$ & $67(88.2 \%)$ & \multirow[t]{2}{*}{0.415 (NS) } \\
\hline $\begin{array}{l}\text {-General } \\
\text { anaesthesia }\end{array}$ & $6(7.9 \%)$ & $9(11.8 \%)$ & \\
\hline -Caucasian & $64(84.2 \%)$ & $61(80.3 \%)$ & \multirow{4}{*}{0.234 (NS) } \\
\hline -African & $1(1.3 \%)$ & $3(3.9 \%)$ & \\
\hline -Arab & $10(13.2 \%)$ & $7(9.2 \%)$ & \\
\hline -Other & $1(1.3 \%)$ & $5(6.6 \%)$ & \\
\hline -Mixed & $3(60.0 \%)$ & $5(55.6 \%)$ & \multirow{3}{*}{0.231 (NS) } \\
\hline breastfeeding & $2(40.0 \%)$ & $1(11.1 \%)$ & \\
\hline $\begin{array}{l}\text {-Exclusive } \\
\text {-Infant formula }\end{array}$ & $0(0.0 \%)$ & $3(33.3 \%)$ & \\
\hline
\end{tabular}

same number of women, 76, were analysed in the study. For each of the two samples certain variables were taken into consideration, including age, parity and the level of education, with the aim of highlighting the aspects that the two groups have in common. A Table is given below, showing the frequency of each category in the two samples in percentage form. The $p$-value was then calculated using the "IBM SPSS STATISTICS" program, which highlights how similar the two groups are to each other (Table 4).

As is seen from the Table, all the $p$-values calculated in relation to the variables used are not statistically significant: from this it may be deduced that the two samples analysed in the study are comparable to each other, since they have very similar characteristics. Most of the afore-mentioned categories have been taken into consideration, as they can influence the perception of pain.

For example, age is a factor that can affect the measurement of VAS, like the parity and the level of education, linked above all to the psycho-social component of pain. Another important parameter appears to be labour before an urgent/emergency caesarean section and the use of synthetic oxytocin in this phase. Breastfeeding was evaluated in new mothers who had undergone a caesarean section in general anaesthesia, as the arrival in the ward of the elastomeric pump containing morphine is expected. The analysis of these data made it possible to evaluate, in part, the effects of this drug in the mother-child dyad: within the experimental arm, in fact, no woman was administered opioid. The following graph shows the progress of breast-feeding in the days following childbirth (Figure 2).

From the percentages obtained during the study, more than half the women in both samples resorted to a mixed type of feeding (excluding with addition of infant formula). $33 \%$ of the new mothers belonging to the control group however fed their new-born with infant formula. There are several reasons for choosing one type of feeding rather than the other, such as the maternal request, the psycho-physical condition of the mother or the health of the new-born. However, taking into 


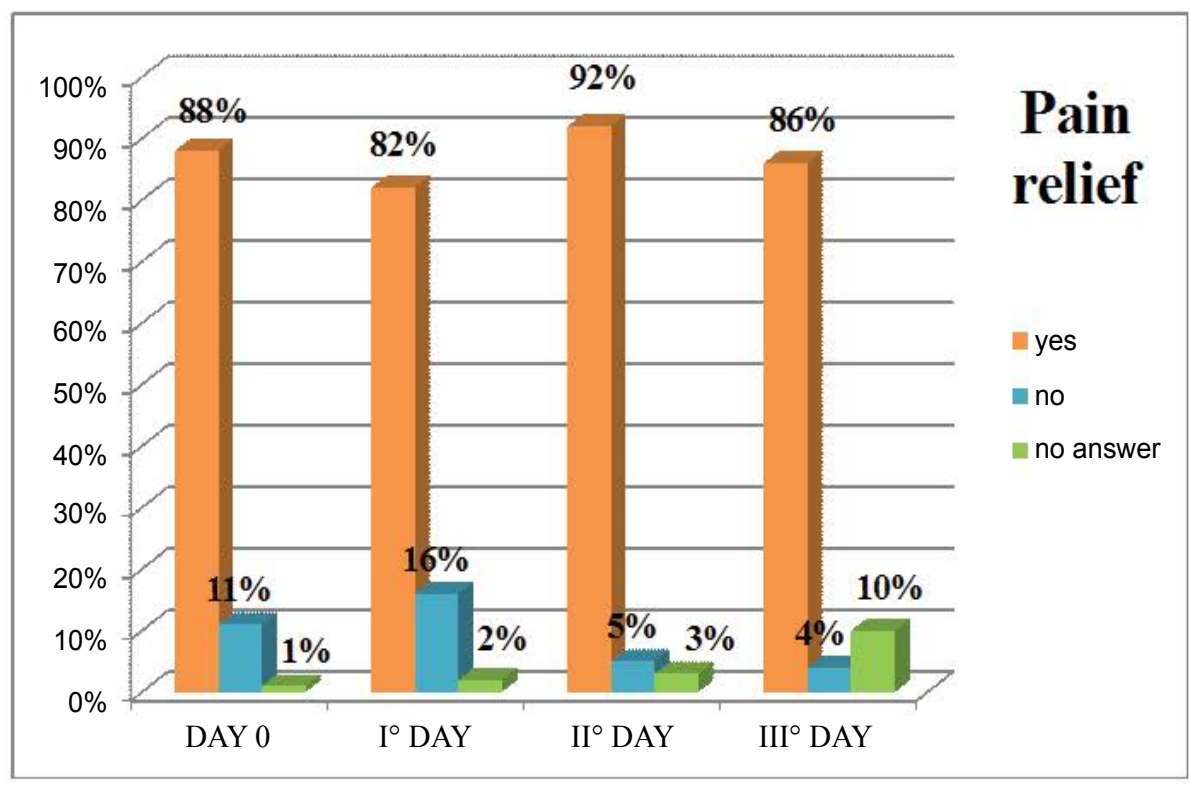

Figure 3: Pain relief.

Table 5: Results.

\begin{tabular}{|l|l|l|l|}
\hline $\begin{array}{l}\text { Category } \\
\text { VAS on day 0 } \\
<4\end{array}$ & Case (76) & Control (76) & P-Value \\
\hline$\geq 4$ & $46(60.5 \%)$ & $41(53.9 \%)$ & $0.412(\mathrm{NS})$ \\
\hline $\begin{array}{l}\text { VAS on day } 1 \\
<4\end{array}$ & $30(39.5 \%)$ & $35(46.1 \%)$ & \\
$\geq 4$ & $21(27.6 \%)$ & $10(13.2 \%)$ & $\begin{array}{l}\text { (statistically } \\
\text { significant) }\end{array}$ \\
\hline $\begin{array}{l}\text { VAS on day } 2 \\
<4\end{array}$ & $55(72.4 \%)$ & $66(86.8 \%)$ & \\
$\geq 4$ & $26(34.2 \%)$ & $19(25 \%)$ & $0.214(\mathrm{NS})$ \\
\hline $\begin{array}{l}\text { VAS on day 3 } \\
<4\end{array}$ & $50(65.8 \%)$ & $57(75 \%)$ & \\
$\geq 4$ & $43(56.6 \%)$ & $45(59.2 \%)$ & $0.742(\mathrm{NS})$ \\
\hline
\end{tabular}

account the mixed breast-feeding rates in both groups, hypotonia and/or hypoglycaemia of the new-born were reported in 4 out of 7 cases. The only temporary neonatal contraindications to breastfeeding for 12-24 hours are respiratory diseases, hypotonia and hypotension. As a result, the wellbeing of the new-born may have affected the administration of infant formula. This hypothesis should be considered pending further studies on the effects of opioids in the mother-child dyad.

\section{Results}

The parameter concerning the VAS, collected for each day of the hospital stay, was taken into consideration for the study. The data obtained from the survey were processed and coded in Excel Tables. Subsequently the $p$-value was calculated using the "IBM SPSS STATISTICS" program, in order to identify the most effective analgesic plan to reduce pain after a caesarean section. The contingency Table is given below, summarising the VAS in the two groups differentiated by days.

Schematization of this parameter shows that control of post-operative pain is achieved in both samples: The $p$-value is not statistically significant on day 0 , on day 2 and on day 3 . This means that the two antalgic treatments can be overlapped in order to obtain the pre-established outcome. From the Table 5, it is seen that the only statistically significant datum is the VAS measured on day 1 . This day of hospitalisation is a delicate post-operative phase for the woman, because it is characterised by greater mobilisation, removal of the bladder catheter and partial recovery of the basic functions. Therefore a timed therapeutic approach was found to be more effective in the management of post-operative pain on day 1 as regards the need for analgesic.

\section{Satisfaction questionnaire}

In order to evaluate the overall psycho-physical wellbeing of the women who have undergone a caesarean section, the influence of the obstetrician administering the therapy, management of the child and relief from pain, questionnaires were distributed to all the women of the experimental arm. The answers were grouped and represented in the form of graphs shown below (Figure 3).

The histogram refers to the first item of the questionnaire, regarding relief from post-operative pain studied each day of hospitalisation: the representation of the data shows that $90 \%$ of the women report wellness throughout the hospital stay. In this case too, it may be noticed how the percentage of the women after childbirth who claim to experience pain relief is slightly less than the others. The chart shows an entry "no answer", which is one of the main disadvantages of self-administered questionnaires: it is sometimes difficult to verify whether the entire sample fully answers the questions present (Figure 4).

This graph represents the answers to the second item of the questionnaire, related to autonomous management of the child (diaper change, breast-feeding, 


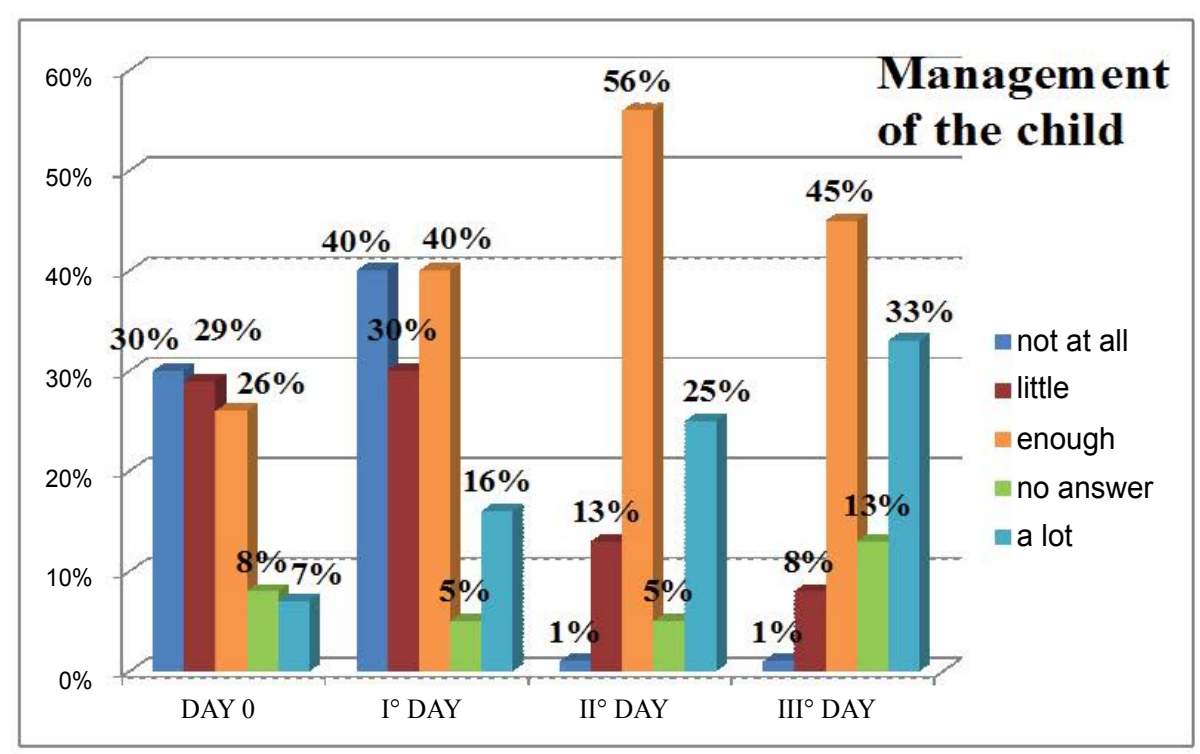

Figure 4: Management of the child.

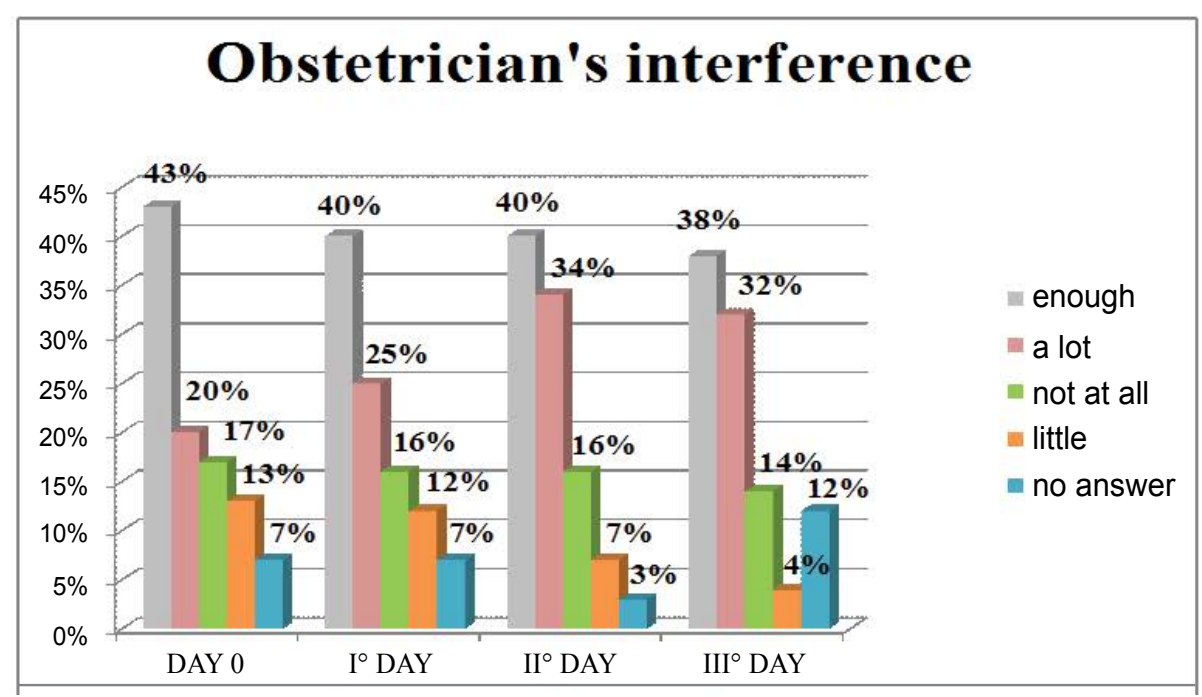

Figure 5: Obstetrician's interference.

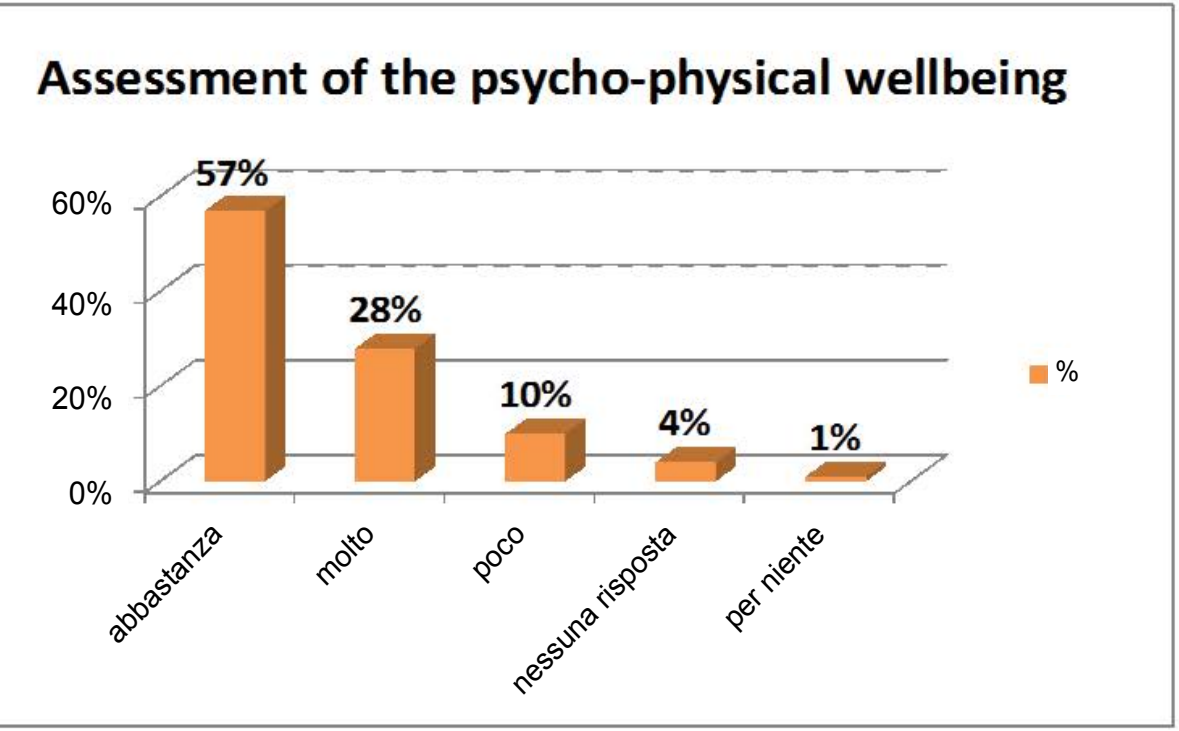

Figure 6: Assessment of the psycho-physical wellbeing.

etc.). The percentages show how women undergoing a caesarean section have greater difficulties in caring for their baby in the early days; however, on the second and third day, the autonomy of the mother increases, 
as well as their mobilisation and the partial recovery of basic functions: this allows them to take better care of their child (Figure 5).

The representation shown above refers to the third item, which concerns the obstetrician's interference in the mother-child-family relationship. It is possible to note how the answers that prevail are "enough" and "very much": The question in the questionnaire does not have any negative or positive meaning; despite being formulated in a neutral way, it was interpreted freely by each woman. It is, therefore, difficult to interpret the data collected, since the connotation of each answer cannot be assessed (Figure 6).

This graph shows the last item of the questionnaire, to which each woman provided an answer before being discharged. This is an overall assessment of the psycho-physical wellbeing achieved during the hospitalisation: $57 \%$ of the mothers belonging to the experimental arm said they were "quite" satisfied with the objective achieved, while in $28 \%$ of the cases their expectations were completely satisfied.

\section{Discussion}

Post-operative pain control in obstetrics is one of the main goals of gynaecologists and obstetricians who take care of the mother after childbirth. This study shows how important it is to obtain the women's satisfaction in terms of psycho-physical wellbeing, by offering them a complete treatment plan suited to their needs.

The purpose of analgesic treatment is to avoid the onset of chronic pain and post-partum depression and to ensure rapid recovery of the basic functions of every woman. Although the data obtained cannot yet be extended to the general population, the analysis conducted is a starting point for the development of future studies, for a detailed study of the topic. Furthermore, the results obtained by the study tell us that the most delicate moment for women after $\mathrm{C}$-Section is the first day: maybe this could be related to an increased mobilization, that may cause pain to women, normally in the laparotomic incision or in the uterus.

This study's aim is to let us think about how important is our help to women after Caesarean Section: All specialists must provide these patients the most accurate supervision they can, in order to discharge independent women who can take care to their babies or themselves on their own.

Lastly, this could be a very important starting point for the future, but more researches are necessary to examine in depth the "pain problem". We think that the purpose of all these studies could be the total wellness of women. We know it's almost impossible to obtain the $100 \%$ wellbeing of patients, but we can at least minimize their painful symptoms.

\section{Conclusions}

Analysing the results obtained, it may be noted that it is during the 24 hours following the surgery that the most adequate pain control is required: In this phase, the mother reports a higher level of pain, presumably due to increased mobilisation and recovery of the physiological functions. This is why, in both the samples studied, the treatment plan used on the $1^{\text {st }}$ day does not seem to be sufficient to obtain psycho-physical wellbeing of the woman. Although on this day the hourly analgesic treatment ensures greater relief from pain, another strategy that can be put in place to ensure adequate analgesia for the new mother is yet to be examined. However, on the other days of hospitalisation, the results obtained with the two treatment plans are superimposable: The women reported wellbeing with treatment with NSAIDS as needed as well as the hourly multimodal treatment.

\section{References}

1. Lavoie A, Toledo P (2013) Multimodal postcesarean delivery analgesia. Clin Perinatol 40: 443-455.

2. Deussen AR, Ashwood P, Martis R (2011) Analgesia for relief of pain due to uterine cramping/involution after birth. Cochrane Database Syst Rev 11.

3. Carvalho B, Butwick AJ (2017) Postcesarean delivery analgesia. Best Pract Res Clin Anaesthesiol 31: 69-79.

4. G Ulufer Sivrikaya Multimodal analgesia for postoperative pain management. Sisli Etfal Training and Research Hospital, Department of $2{ }^{\text {nd }}$ Anesthesiology and Reanimation, Istanbul, Turkey.

5. Charles S Cleeland (1991) The Brief Pain Inventory (BPI). 